\title{
3D Spatial Visualisation Skills Training Application for School Students Using Hologram Pyramid

\author{
Rose Khairunnisa Roslan ${ }^{\#}$, Azlina Ahmad \\ \# Institute of Visual Informatics, Universiti Kebangsaan Malaysia, Malaysia \\ Email :ros.nissa@gmail.com,azlinaivi@ukm.edu.my
}

\begin{abstract}
Students need good visualisation skills to perform well in the field of Science, Technology, Engineering and Mathematics (STEM). However, two preliminary studies conducted with six teachers and fifty (50) Year 4 students at a local school showed that most of them are facing difficulties in visualizing 3D objects. From these findings and review of literature, we proposed a conceptual model called 3D Spatial Visual Skills Training (3D SVST) model. The 3D SVST model was applied as a basis to develop an application to improve 3D visualisation skills among elementary school students using a floating image technology known as hologram pyramid. In this paper, we report the findings from evaluation of students' performance in visualisation skills test using 3D SVST application. Fifty (50) Year 4 students from a local school in the state of Selangor participated in the study. Two types of tests were conducted on students; 3D visualisation skills test using paper and 3D visualisation skills test using hologram pyramid. The tests include Paper Folding Task (PFT), Mental Rotating Task (MRT) and Virtual Building Component (VBC). The results show that students' visualisation skills improved when using the hologram pyramid application. The study also found that students performed better in PFT but lower in MRT and VBC. From the findings, we can conclude that hologram pyramid has a positive impact on visualisation skills of students. Therefore, it has the potential to be used in classroom to complement other teaching and learning materials
\end{abstract}

Keywords - Visualisation skills; Hologram pyramid; STEM

\section{INTRODUCTION}

There are various definitions of visualisation, however, the term means to imagine and describe. Visualisation skill is one of the main components of human intelligence and it is relevant in many areas of employment, education and training programs. Visualisation skill also refers to the ability of mental representation and manipulation of visual spatial information. Visualisation skill is related to the theory of cognitive development and intellectual development proposed by Jean Piaget. According to [1], visualisation skill is the ability of the mind associating with sharp observation, visual thinking, mental images, and sensitivity to shapes and so on. This skill is needed by students to interpret an object visually and abstractly before transform it into verbal or graphic [2]. Visualisation is the ability of students to imagine and design objects that can be altered from multiple views. In summary, visualisation refers to individual's skill in viewing an object and parts of the object and thinking either in two dimension or in three dimension in their minds. In general, visualisation skill help students provide information that is not stated verbally or other instruction in teaching and learning [3]. Spatial visualisation is a specific type of visualisation which is related to objects in $2 \mathrm{D}$ and $3 \mathrm{D}$ space. According to [4], spatial visualisation is a skill to present and mentally manipulate visual objects. This skill is assessed using some tasks such as folding paper and rotating objects mentally, where one has to imagine the change of shape of objects using their mind.

[5] have shown that students who have good ability to visualise, performed better in STEM related curriculum. It is supported by [6] which according to him, students with higher visualisation skills easier to understand STEM subjects. Programs in in this field require students' ability to process visual information as well as the ability to develop mental images, draw diagrams or to develop symbols to represent their imagination. It is important for students to improve their visualisation skills if they want to understand better in STEM related subjects. A study by [7] found that there is a relationship between visualisation skills with students' achievement in science and mathematics. A study by [8] also supported that students who have high level of visualisation skills get better results in learning science and math compared to students who have a low level of visualisation skills. According to [9], many students face difficulties in describing a complex question with a two dimensional representation. This problem is more noticeable 
when involved students who have low level of visualisation skills [10]. Therefore, research on methods to improve students' visualisation skills through the teaching and learning is very crucial and relevant.

The rapid development of information and communication technology (ICT) is affecting various aspects of human life, including education. ICT in educational contexts is an electronic network for searching, collecting, storing, processing, transporting and delivering information effectively and quickly [11]. Today, hologram technology is one of the rapidly evolving technologies. Although hologram technology in educational environment is still new, but it has potential in helping students' learning process [12]. The use of hologram technology in teaching and learning are able to form active students' in the process of knowledge acquisition. It can provide opportunities for students to observe, classify, build and modify their personal knowledge aside from participating actively and collaboratively. Therefore, a study was conducted to determine the effect of using hologram pyramid, a floating image technology on students' visualisation skills.

\section{3D SPATIAL VISUAL SKILLS TRAINING (3D SVST) MODEL}

By relating the observations made during preliminary studies to learning theories, the 3D SVST model is formulated. The model is shown in Figure 1. The 3D SVST model is formulated for the purpose of training 3D spatial visual skills among learners and to improve their cognitive processes during visualisation. The model comprised of three (3) layers which are relevant in spatial visualization training. They are namely (1) Spatial Visual Skills, (2) Theories of Learning and (3) Learning Approach. Four (4) learning theories related to this training is taken into consideration. These include Spatial Theory, Dual Code Theory, Constructivist Theory and Visual Thinking Model.

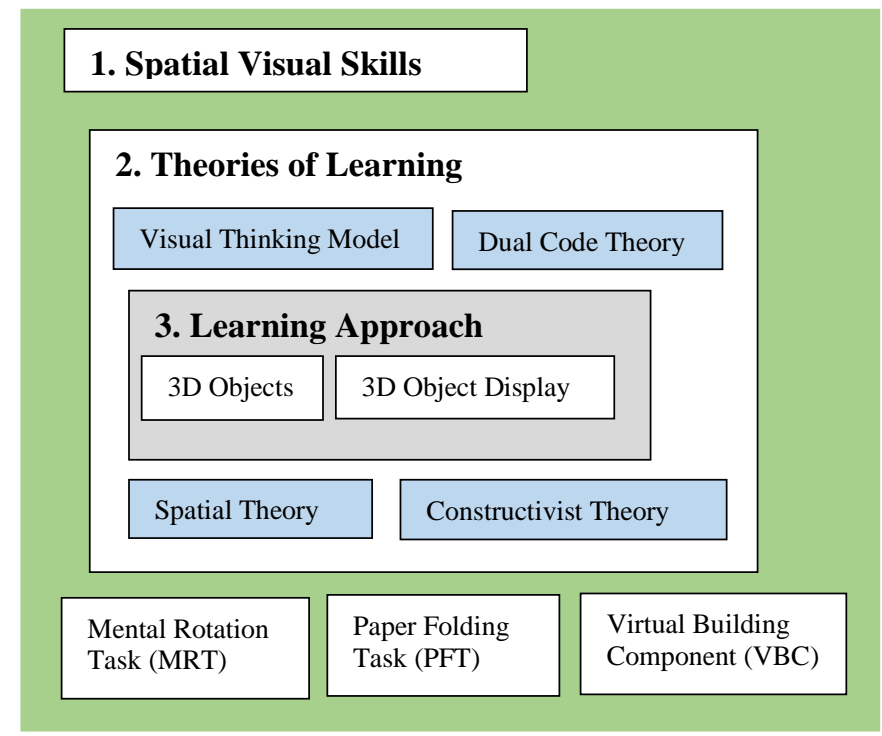

Fig.1 3D Spatial Visual Skills Training (3D SVST) Model
Today, there are a lot of research in education using cutting-edge technology such as touch-screen technology, augmented reality technology (AR) as well as virtual reality technology (VR) as a tool to test the skills of visualisation [13], [14], [15]. However, we chose one approach that can implement the 3D SVST model that is the hologram pyramid. It is a floating image technology that can display 3D object within its space. Three dimensional hologram technology is increasing its popularity today since it is suitable to be used in developing visualisation skills among learners. This technology requires an LCD screen as well as a four-sided glass pyramid. The reflected image through the LCD screen appears in the pyramid and appears to float in the air. This technology is capable of displaying 3D images in a $360^{\circ}$ view. Through this hologram pyramid, users can give their visual impact of 3D objects from all directions side. Users can also experience the thrill of real effects without the need 3D glasses. This technology uses the concept of Pepper's Ghost illusion technique in a theater created by Professor John Henry Pepper (1821-1900) and the English engineer Henry Dircks (1806-1873) in the 19th century. The technique works using the reflection from a mirror. A glass beaker is placed on the stage at an angle of 45 degrees to get a reflection from under the stage, as shown in Figure 2. Thus, the viewer can see the figure appearing on stage directly through the air and interact with other actors. A study by [16] found that hologram technology brings positive impact on learning.

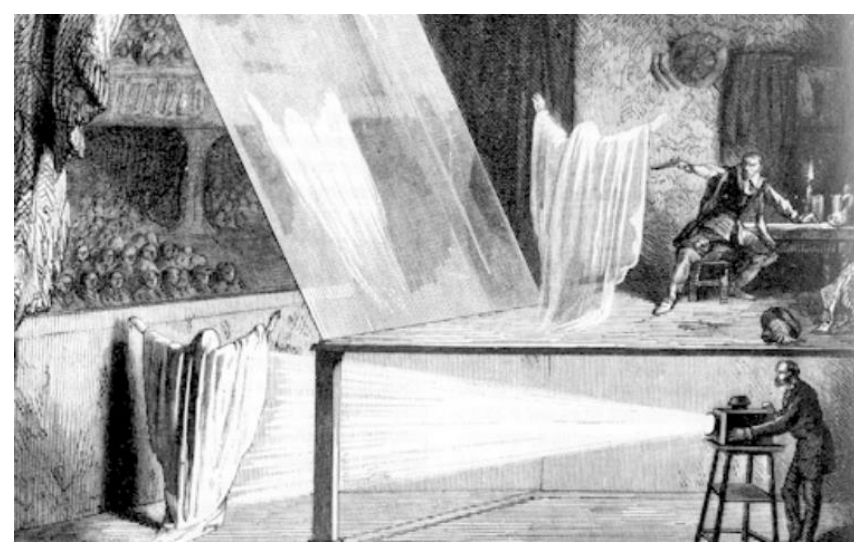

Fig. 2 The principle concept of Pepper's Ghost Effect

\section{DEVELOPMENT OF 3D SVST APPLICATION USING HOLOGRAM PYRAMID}

The development of application using hologram pyramid based on 3D SVST model involves design of hardware and software components. Hardware components comprise of a pyramid-shaped acrylic glass and a display monitor. The hologram pyramid is the image reflection component while the display monitor is the image generation component. Table 1 shows the hardware requirements needed for the development of 3D SVST application. 
TABLE 1. HARDWARE REQUIREMENTS OF 3D SVST APPLICATION

\begin{tabular}{|l|l|l|l|}
\hline Component & Composition & Design criteria & Material \\
\hline \multirow{2}{*}{$\begin{array}{l}\text { Image } \\
\text { reflection }\end{array}$} & Pyramid & $\begin{array}{l}\text { - Clear Image } \\
\text { Reflection } \\
\text { - Transparent }\end{array}$ & $\begin{array}{l}\text { Acrylic or } \\
\text { glass }\end{array}$ \\
\cline { 2 - 5 } & $\begin{array}{l}\text { Support } \\
\text { Structure }\end{array}$ & $\begin{array}{l}\text { - Slim } \\
- \text { Stable } \\
- \text { No reflection } \\
\text { of light }\end{array}$ & $\begin{array}{l}\text { Plastic or } \\
\text { polycarbonate }\end{array}$ \\
\hline $\begin{array}{l}\text { Image } \\
\text { generation }\end{array}$ & Computer & $\begin{array}{l}\text { - Sharp image } \\
- \text { Higher } \\
\text { graphic card }\end{array}$ & - LCD High Contrast \\
\hline
\end{tabular}

Image reflection component also consists of a structure that supports the pyramid itself, as shown in Figure 3. The four triangular-shaped sides, which form a pyramid, are made of transparent acrylic glass. To reflect the image from horizontal position to vertical position in front of students, the sides must be tilted at an angle of $45^{\circ}$ as shown in Figure 4. The image generation component is a computer display monitor, which is placed horizontally on a surface. The image generation component needs to produce sharp image without any distortion.

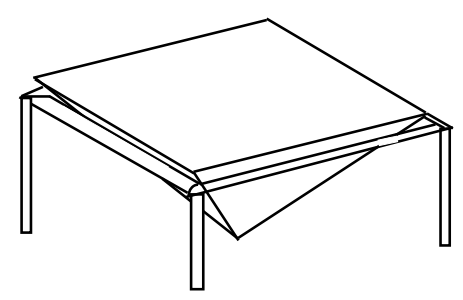

Fig. 3 Hologram pyramid structure design

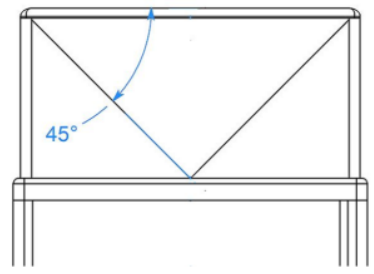

Fig. 4 Hologram pyramid triangular-shaped sides at $45^{\circ}$

Development of 3D objects used in the application involved modeling of the objects, animations, and also programming of the 3D objects to display at four sides of the specified quadrants. Color of object is also emphasized to attract students' attention. Spatial visualisation skills test used in the 3D SVST application is a standardized test used to measure an individual's ability to visualise. Each visualisation skill test used to measure specific visualisation skills. Among the common standard visualisation skills test used are Mental Rotating Task (MRT), Paper Folding Task (PFT) and Virtual Building Component (VBC). MRT is to test the ability to rotate mentally, PFT is to test the ability to stretch and fold mentally and VBC is to test the ability to cut $3 \mathrm{D}$ objects mentally and to test the understanding of building technology and also the concept of 3D modeling in building design. In this study, spatial visualisation skills were assessed using MRT, PFT and VBC tests. In MRT test, students were asked the final representation of an object when it is rotated in a certain direction (Figure 5). In PFT tests, students were shown a paper that has drawing lines and were asked to imagine the final representation of an object when the folding paper is opened according to line (Figure 6). In VBC test, students were given a $3 \mathrm{D}$ object and they were required to identify the representation of the object when transformed into 2D through a certain viewing angle (Figure 7). Each section of the test consists of two questions
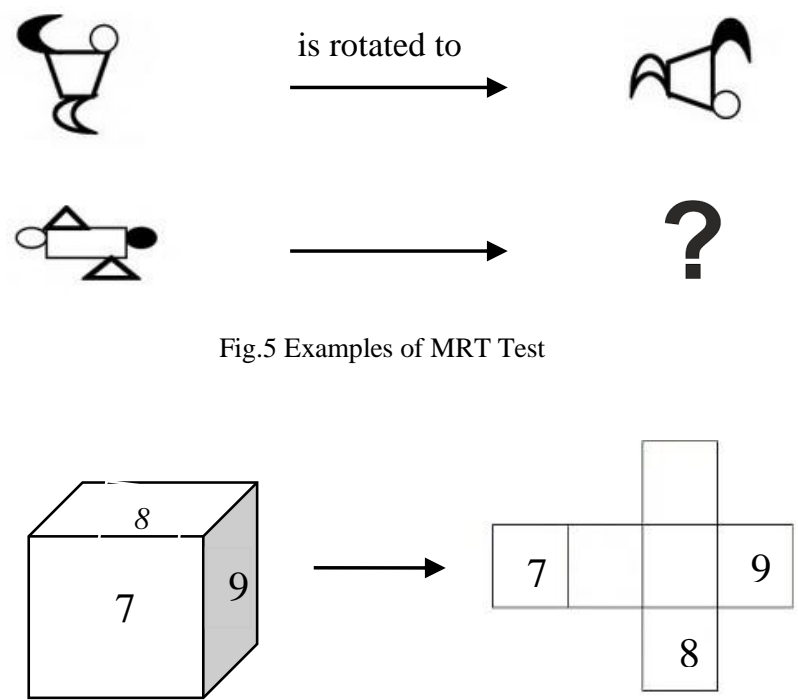

Fig. 6 Example PFT Test (folding paper is opened according to line)

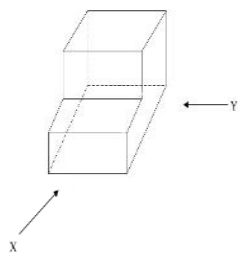

X)

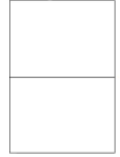

Y)

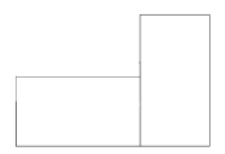

Fig. 7 Example VBC Test

\section{METHODOLOGY}

A total of (50) Year 4 students from a local school in the state of Selangor participated in a study using 3D SVST application. Thirty-two (36) people were male students and fourteen (14) were female students. Participants were students aged 10 years from different race: Malay, Chinese and Indian. Pre-test and post-test instruments were developed based on the standardized visualisation skills test. The tests were divided into three sections: Section A- Mental Rotating Task (MRT), Section B- Virtual Building Component (VBC), and Section C- Paper Folding Task (PFT). Each section has two questions. The objective of the pre-test is to get the performance level of students' visualisation skill through exercises using ordinary paper test 
before they were exposed to hologram pyramid. Once pretest has been conducted, participants were given exposure to visualisation skills training using the hologram pyramid. Then, the participants were asked to sit for a post-test. Paired sample t-test was used to determine whether there is a significant difference between mean scores of pre-test and post-test. The students' achievement on pre-test and post-test were scored according to four levels as shown in Table 2.

TABLE 2. ACHIEVEMENT LEVELS

\begin{tabular}{|l|l|}
\hline $\begin{array}{l}\text { Score marks } \\
(\%)\end{array}$ & $\begin{array}{l}\text { Visualisation Skill } \\
\text { Level }\end{array}$ \\
\hline $80-100$ & High \\
\hline $60-79$ & Average \\
\hline $40-59$ & Low \\
\hline $0-39$ & Very Low \\
\hline
\end{tabular}

\section{DISCUSSION AND ANALYSIS OF FINDING}

Analysis of the results were carried out using t-test to determine level of improvement of students' visualisation skill. Table 3 shows the detail results obtained from pre-test and post-test conducted. The results show that the mean percentage of pre-test is 40.57 which is interpreted as low based on the levels given in Table 2. However, from the post-test, it can be seen that the mean percentage is 67.98 which is interpreted as average. The results show that visualisation skills of students improved after using the 3D SVST application using hologram pyramid. In fact, results show that visualisation skills of students improved after using hologram pyramid for all sections; MRT, VBC and PFT. Figure 8 shows the comparison of marks of participants for each of the three sections.

\section{TABLE 3: T-TEST FOR VISUALISATION IMPROVEMENT}

\begin{tabular}{l|l|l|l|l|l|l} 
Test & \multicolumn{2}{c}{ N Mean } & \multicolumn{1}{c}{$\begin{array}{c}\text { Standard } \\
\text { deviation }\end{array}$} & df & \multicolumn{2}{c}{ Sig } \\
\cline { 1 - 1 } $\begin{array}{l}\text { Pre- } \\
\text { Test }\end{array}$ & 50 & 47.30 & 27.241 & \multirow{2}{*}{4} & - & $0.004^{*}$ \\
\hline $\begin{array}{l}\text { Post- } \\
\text { Test }\end{array}$ & 50 & 61.33 & 17.321 & & 3.845 & \\
\hline
\end{tabular}

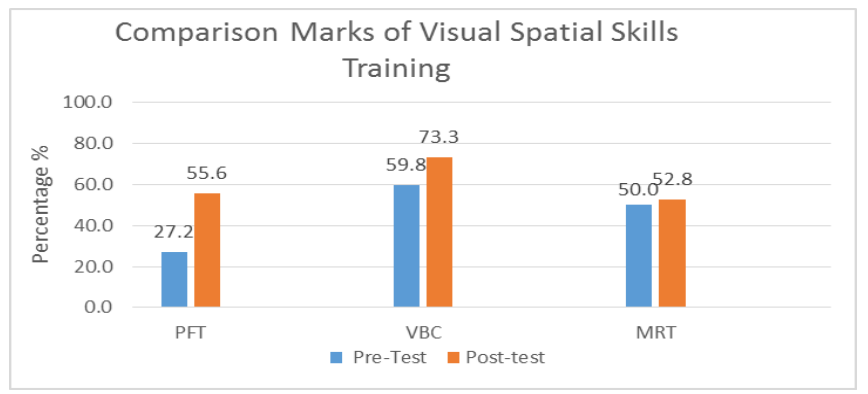

Fig. 8 Mean Score for MCT, VBC and PFT in pre-test and post-test
From Figure 8, we observed that students' performance is lowest in PFT pre-test compared to both VBC and MRT pretests. After the students were introduced the 3D VSVT application using hologram pyramid, their performance in the post-tests were improved especially for the PFT section. The mean score for PFT has increased by 28.4 percent. A possible explanation for the significant improvement of students' performance in the PFT test is that the students have better visualisation of object with animation of paper folding that floats in the 3D space of the hologram pyramid. This visual image representation resembled real objects. Thus, it is easier for students to create abstract images in their mind which helped them when answering related questions. From the findings, we believe that floating image technology using hologram pyramid can improve students' visualisation skills effectively. Therefore, this approach of using hologram pyramid can be applied in teaching and learning for school students to improve their visualisation skills. The approach of using hologram pyramid can attract students' attention and interest in learning. Students are able to view $3 \mathrm{D}$ visual representation of floating objects in $3 \mathrm{D}$ space which are more realistic.

\section{CONCLUSION}

Generally, students need help to improve their visualisation skills in order to perform better in STEM related subjects. This study showed that, floating image technology using hologram pyramid can provide a potential solution to improve visualisation skills of students. Visualisation skill is important for students to develop abstract imagination of objects or concepts. In this paper, we discussed the development of 3D SVST application using hologram pyramid which has been proven effective in improving students' visualisation skills. The results of pretest and post-test conducted with fifty (50) Year 4 students showed significant improvement in all three sections of the tests: PFT, VBC and MRT. Thus, the approach of using hologram pyramid to display $3 \mathrm{D}$ objects in space to improve visualisation skills of students can be implemented in schools. With better visualisation skills, students' performance in STEM related subjects will improve. This can create students' interest in the field of Science, Technology, Engineering and Mathematics.

\section{ACKNOWLEDGMENT}

We would like to thank Universiti Kebangsaan Malaysia for the grant (STEM 2014-011) approved for this research.

\section{REFERENCES}

[1] Widad Othman, \& Lee, Ming Foong (2008) Peningkatan tahap kognitif visualisasi pelajar jurusan teknikal melalui latihan-latihan visualisasi. In: International Conference on the Education of Learner Diversity 2008, 26-27 August 2008, Marriot Hotel,Putrajaya.

[2] Mohd Salleh Tahar, Ahmad Esa, Mohd Bekri Rahim, Jamil Abd Baser, Syazwani Shuib \& Yahya Buntat. (2011) Keberkesanan Penggunaan Cd Interaktif Lukisan Isometrik terhadap Kemahiran Visualisasi Pelajar. Journal of Technical, Vocational \& Engineering Educational Volume 3 September 2011, Pages 104-115/ISSN: 22317376 
[3] Dayang Suryati Abang Ibrahim \& Abdullah Mat Rashid. (2015) Pengaruh Pencapaian Akademik dan Tahap Memori Visual Jangka Pendek terhadap Tahap Kemahiran Visualisasi Murid yang Mengambil Mata Pelajaran Lukisan Kejuruteraan. International Journal of Education and Training (InjET) 1(2) November: 1-8 (2015)

[4] Turgut, M., \& Uygan, C. (2013). Spatial ability training via 3D modelling software. In E. Faggiano \& A. Montone (Eds) Proocedings of the 11th International Conference on Technology in Mathematics Teaching-ICTMT11, (pp. 292-297). University of Bari, 9- 12 July 2013, Italy: Università degli Studi di Bari Aldo Moro

[5] Stieff M. \& Uttal D. 2015. How Much Can Spatial Training Improve STEM Achievement? A Review Article. Educ Psychol Rev. DOI 10.1007/s10648-015-9304-8

[6] Wai, J., Lubinski, D., \& Benbow, C. P. (2009). Spatial ability for STEM domains: Aligning over 50 years of cumulative psychological knowledge solidifies its importance. Journal of Educational Psychology, 101, 817-835

[7] Monteiro, C 2013, 'The making of an effective teacher: born or made?' New Teacher Center, weblog post, 31 July 2013, viewed 17 Oct 2017, <http://www.newteachercenter.org/blog/> making-effective-teacher-born-or-made

[8] Hoffler, T. N., \& Leutner, D. (2011.) Computers in Human Behavior The role of spatial ability in learning from instructional animations Evidence for an ability-as compensator hypothesis, 27, 209-216

[9] Danakorn, N., Noor Dayana, A., \& Norafffandy, Y. (2013). Mobile Augmented Reality: Thepotential for education. 13th International Educational Technology Conference, Procedia-Social and Behavioral Sciences, 103, 657-664

[10] Berney, S., Bétrancourt, M., Molinari, G. \& Hoyek, N. (2015). How spatial abilities and dynamic visualizations interplay when learning functional anatomy with 3D natomical models. Anatomical sciences education.

[11] Azwan Ahmad, Abdul Ghani Abdullah, Mohammad Zohir Ahmad \& Abd. Rahman Hj. Abd Aziz. (2005). Kesan Efikasi Kendiri Guru Sejarah Terhadap Amalan Pengajaran BerbantukanTeknologi Maklumat dan Komunikasi (ICT). Jurnal Penyelidikan Pendidikan

[12] Sudeep U. 2010. Use of 3D Hologram Technology in Engineering Education. IOSR Journal of Mechanical and Civil Engineering (IOSR-JMCE). ISSN: 2278-1684, PP: 62- 67

[13] Dunleavy, M., \& Dede, C. (2014). Augmented reality teaching and learning. In Handbook of research on educational communications and technology (735-745). Springer New York.

[14] Martin-Dorta N., Saorin J.L., \& Contero M. (2011) Web-based Spatial Training Using Handheld Touch Screen Devices. Journal of Educational Technology \& Society. Vol. 14, No. 3, Knowledge Visualization for Learning and Knowledge Management (July 2011), pp. 163-177.

[15] Chang, G., Morreale, P., \& Medicherla, P. (2010). Applications of augmented reality systems in education. In D. Gibson \& B. Dodge (Eds.), Proceedings of Society for Information Technology \& Teacher Education International Conference 2010, 1380-1385. Chesapeake, VA: AACE

[16] Figueiredo MJG, Cardoso PJS, Goncalves CDF, Rodrigues JMF (2014). Augmented reality and holograms for the visualization of mechanical engineering parts. Information Visualisation (IV), 2014 18th International Conference, 368-373. 